\title{
Global Anesthesia Workforce Crisis: A Preliminary Survey Revealing Shortages Contributing to Undesirable Outcomes and Unsafe Practices
}

\author{
Gerald Dubowitz $\cdot$ Sarah Detlefs $\cdot$ K. A. Kelly McQueen
}

Published online: 1 October 2009

(c) The Author(s) 2009. This article is published with open access at Springerlink.com

\begin{abstract}
Background The burden of disease, disability, and mortality that could be averted by surgery is growing. However, few low and middle income countries (LMICs) have the infrastructure or capacity to provide surgical services to meet this growing need. Equally, few of these countries have been assessed for key infrastructural capacity including surgical and anesthesia providers, equipment, and supplies. These assessments are critical to revealing magnitude of the evolving surgical and anesthesia workforce crisis, related morbidity and mortality, and necessary steps to mitigate the impact of the crisis.

Methods A pilot Internet-based survey was conducted to estimate per-capita anesthesia providers in LMICs. Information was obtained from e-mail respondents at national
\end{abstract}

G. Dubowitz $(\bowtie)$

Department of Anesthesia, University of California San

Francisco, 505 Parnassus Avenue, San Francisco, CA 94143,

USA

e-mail: dubowitz@anesthesia.ucsf.edu; gerald@globalPAS.org

URL: www.globalPAS.org

G. Dubowitz

Global Partners in Anesthesia and Surgery, San Francisco, USA

S. Detlefs

Boston University, Boston, MA, USA

K. A. Kelly McQueen

Valley Anesthesiology Consultants, Suite 500, 2901 N Central

Avenue, Phoenix, AZ 85012, USA

K. A. Kelly McQueen

Harvard Humanitarian Initiative, Cambridge, MA, USA

K. A. Kelly McQueen

Mayo Clinic, Scottsdale, AZ, USA health care addresses, and from individuals working incountry on anesthesia-related projects.

Results Workers from 6 of 98 countries responded to direct e-mail inquiries, and an additional five responses came from individuals who were working or had worked in-country at the time of the survey. The data collected revealed that the per-capita anesthesia provider ratio in the countries surveyed was often 100 times lower than in developed countries.

Conclusions This pilot study revealed that the number of anesthesia providers available per capita of population is markedly reduced in low and lower middle income countries compared to developed countries. As anesthesia providers are an integral part of the delivery of safe and effective surgical care, it is essential that more data is collected to fully understand the deficiencies in workforce and capacity in low and middle income countries.

\section{Introduction}

Economies of the world are divided according to gross national incomes (GNI) per capita. The result separates countries into low income, with a GNI per capita of $\$ 975$ (US dollars) or less; lower middle income, with a GNI of $\$ 976-\$ 3,855$; upper middle income, $\$ 3,856-\$ 11,905$; and high income, $\$ 11,906$ or more [1]. The World Health Organization (WHO) uses these World Bank descriptions of countries to group countries by economy and also by public health indicators. Disparities between global healthcare needs and the available workforce in low and middle income countries (LMICs) is a pressing problem in today's global health arena [2-4]. Within this global workforce crisis, is a much-neglected subgroup, the 
medical professionals needed to deliver anesthetic, perioperative, and surgical care [2-9].

The magnitude of the global burden of surgical disease and its impact on global healthcare resources was first outlined in 2006 as part of Disease Control Priorities in Developing Countries, published by the World Health Organization and World Bank. The authors presented data to suggest that the burden of surgical diseases would eclipse that of HIV, tuberculosis, and malaria by the year 2026 [10]. In spite of a number of global healthcare initiatives, both past and present, the problem of a lack of provision for anesthetic care remains virtually unchanged. Therefore, addressing the global shortage of anesthesia providers is pivotal in any program which aims to tackle the burden of surgical disease $[6,11]$. There is also a clear and unmet need for capacity building to complement workforce expansion in healthcare in low and middle income countries [2, 3, 5-10, 12-14].

While the anesthesia workforce crisis is evident in low and middle income countries worldwide, it is widely represented in sub-Saharan Africa, with respect to the issues faced in recruiting and retaining an anesthetic workforce and finding innovative solutions to better address this persistent problem $[3,6,11,15]$. There is a widening gap between the need for healthcare and the number of available providers. The global shortage of healthcare workers is estimated to be at 4.2 million, with approximately one million more workers needed in sub-Saharan Africa alone $[2,4]$. Africa bears $25 \%$ of the global burden of disease with only $2 \%$ of the world's workforce $[5,10]$. For surgical disease, the numbers of healthcare workers in anesthesia and perioperative care are estimated to be similarly depressing, but still poorly understood due to a profound lack of research on the topic [6,7]. The problem goes far beyond shortages of anesthesiologists alone, and includes inadequate nursing and surgical staffing, as well as an overall neglected health infrastructure.

Importantly, the shortage of anesthesia providers in LMICs has a direct effect on the anesthesia-related morbidity and mortality, as well as lower rates of surgery in countries already restricted by resources and capacity [11, 16-19].

\section{Methods}

A brief questionnaire was designed as the basis for a descriptive pilot study to assess numbers of anesthesia providers in 43 low and 55 lower middle income countries. E-mail contacts from the World Health Organization (WHO) and Ministry of Health $(\mathrm{MoH})$ were collected for 88 of the 98 countries designated as low income or lower middle income as defined by the WHO. Of the low and lower middle income countries targeted for information $(n=98) 88$ had published e-mail contacts with the WHO or through their $\mathrm{MoH}$; North Korea, Kyrgyz Republic, Algeria, Armenia, Bosnia, Herzegovina, Fiji, Moldova, Guyana, and Peru had no electronic point of contact from either the WHO or a MoH. Data were also collected directly from anesthesia providers who had been or were working in a LMIC and had direct access to the country's healthcare demographics.

All of the information obtained in this pilot assessment is considered to be best estimates. No information was collected on licenses or other country-specific information for the anesthesia providers.

\section{Results}

E-mail responses were ultimately received from workers in 6 of 88 possible low income or lower middle income countries, and direct information was received from 8 of 43 low income countries where the information had been personally gathered by visiting physicians. The electronic responses received were from Emergency and Humanitarian Action (EHA) WHO officers and WHO in-country officers. All electronic responses, except for that from Zambia, indicated numbers and types of anesthesia providers, including physician and non-physician anesthesia providers. The EHA Officer from Zambia did not include the data for non-physician anesthesia providers. The response from Yemen specifically outlined the title and level of anesthesia providers in-country.

WHO Officers from Tanzania, Zimbabwe, and Zambia stated that they received the information from the Ministry of Health. Similarly, the Afghanistan WHO technical officer obtained the information from the Ministry of Public Health. The WHO officers, who responded from Yemen, and Swaziland, did not state where they received the data.

Personally gathered information was obtained from Senegal, Cameroon, Benin, the Democratic Republic of Congo, Rwanda, Uganda, Cote d'Ivoire, and Ethiopia on physician anesthesia providers.

Most LICs and lower MICs surveyed, except Swaziland, have ratios of less than 1 physician or non-physician anesthesia provider per 100,000 population, as shown in Figs. 1 and 2. The Democratic Republic of Congo had the lowest number of physician anesthesia providers with 0.02 providers per 100,000 people, and Zimbabwe has the highest ratio with 0.3 physician providers per 100,000 people (Fig. 1). Yemen has the lowest number of physician or non-physician anesthesia providers, with 0.07 providers per 100,000 people, while Swaziland had the highest 
Fig. 1 Physician anesthesia providers per 100,000 people in low and middle income countries (LMICs)
Fig. 2 Physician and nonphysician anesthesia providers per 100,000 people in LMICs
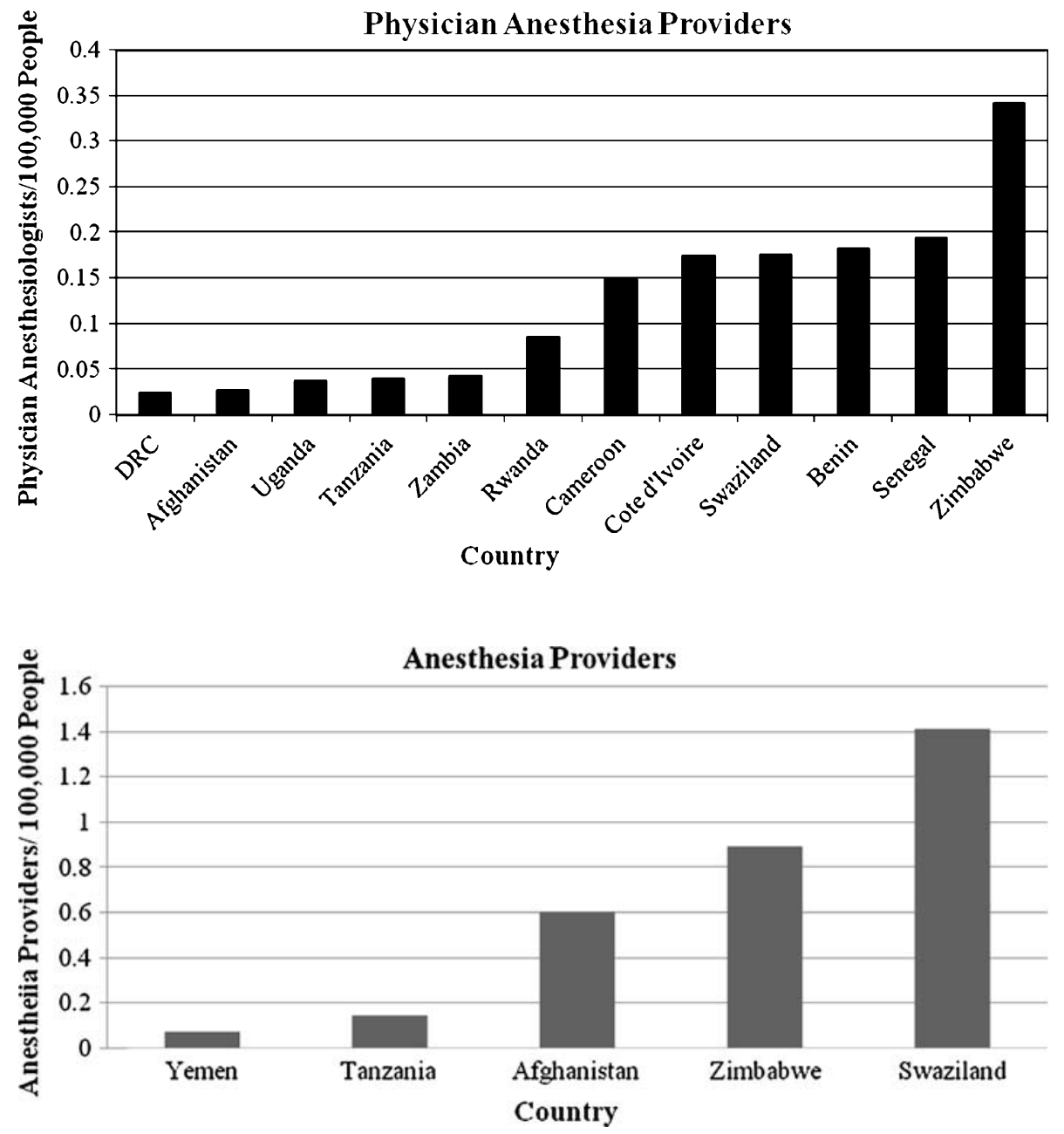

number of physician and non-physician anesthesia providers, with 1.41 providers per 100,000 people (Fig. 2).

From the electronic responses, Tanzania, Zimbabwe, and Yemen all stated that they had anesthesia residency training programs. In Tanzania, there are two residency programs with four residents in training. In Zimbabwe, there is one residency program that trains 150 residents per year. Finally, Yemen also had one residency program that trains 86 residents per year. Correspondents from Zambia and Afghanistan noted that they did not have residency programs within their countries. The EHA officer from Swaziland did not provide information regarding anesthesia residency programs in Swaziland. Personally collected data show Uganda has two residency programs with 10 residents in training.

\section{Discussion}

The numbers of trained anesthesia providers are known to be deficient in LMICs. However, no single source of information exists to determine the numbers of practicing anesthesia providers per capita or the numbers of providers being trained in each of these countries. While the WHO tracks the number of physicians per country information about specific numbers of specialized providers are often only known by national ministries of health [20]. Where physician numbers are very low, assumptions can be made about the even fewer numbers of trained specialists. Therefore, in many LMICs there are often only a few or no anesthesia providers for millions of people.

Traditionally, minimal resources have been allocated for diseases or conditions for which surgical intervention is necessary in LMICs [6-9, 14, 21]. The absence of these resources in turn has limited the workforce component, surgical infrastructure and capacity. Public health indicators collected by the WHO clearly document that population health indicators are directly related to the state of the healthcare workforce [22]. Countries with low physician rates, limited hospital beds, and severely constricted financial resources (percentage of GNI allocated for health) have predictably low average life expectancy, high infant mortality rates, and high under five mortality rates (Table 1) Further, countries with limited hospital and 
Table 1 Public health indicators for the United States (USA) and for low and middle income countries (LMICs), by year reported

\begin{tabular}{lllll}
\hline Location & $\begin{array}{l}\text { Life expectancy at birth } \\
\text { (years), 2006 }\end{array}$ & $\begin{array}{l}\text { Under-5 mortality (per 1,000 } \\
\text { live births), 2006 }\end{array}$ & $\begin{array}{l}\text { Infant mortality (per 1,000 } \\
\text { live births), 2006 }\end{array}$ & $\begin{array}{l}\text { Maternal mortality (per 100,000 } \\
\text { live births), 2005 }\end{array}$ \\
\hline Afghanistan & 42 & 257 & 165 & 1,800 \\
Benin & 55 & 148 & 88 & 840 \\
Cameroon & 51 & 149 & 87 & 1,000 \\
Cote d'Ivoire & 53 & 127 & 90 & 810 \\
Democratic & 47 & 205 & 129 & 1,100 \\
Republic of & & & & 1,300 \\
Congo & & 160 & 97 & 980 \\
Rwanda & 52 & 116 & 60 & 390 \\
Senegal & 59 & 164 & 112 & No data \\
Swaziland & 42 & No data & No data & 550 \\
Tanzania & No data & 134 & 78 & 11 \\
Uganda & 50 & 8 & 7 & 430 \\
USA & 78 & 100 & 75 & 830 \\
Yemen & 61 & 182 & 102 & 880 \\
Zambia & 43 & 85 & 55 & \\
Zimbabwe & 43 & &
\end{tabular}

Table 2 Public health indicators of medical care providers and hospital beds in the USA and LMICs, by year reported

\begin{tabular}{lclr}
\hline Location & $\begin{array}{l}\text { Hospital beds } \\
\text { (per 10,000 population) }\end{array}$ & $\begin{array}{l}\text { Number of other } \\
\text { health service providers }\end{array}$ & $\begin{array}{l}\text { Number of } \\
\text { physicians }\end{array}$ \\
\hline Afghanistan & $4(2003)$ & No data & $5,970(2004)$ \\
Benin & $5(2005)$ & $218(2004)$ & $311(2004)$ \\
Cameroon & $15(2006)$ & $16(2004)$ & $3,124(2004)$ \\
Cote d'Ivoire & $4(2006)$ & $172(2004)$ & $2,081(2004)$ \\
Democratic Republic of the Congo & $11(2005)$ & $1042(2004)$ & $5,827(2004)$ \\
Rwanda & $16(2007)$ & $1,047(2004)$ & $432(2004)$ \\
Senegal & $1(2007)$ & $704(2004)$ & $594(2004)$ \\
Swaziland & $21(2006)$ & $1,316(2004)$ & $171(2004)$ \\
Uganda & $11(2006)$ & $4,128(2004)$ & $2,209(2004)$ \\
United States of America & $32(2005)$ & $4,138,567(2000)$ & $730,801(2000)$ \\
Yemen & $7(2006)$ & No data & $6,739(2004)$ \\
Zambia & $22(2004)$ & $3,330(2004)$ & $1,264(2004)$ \\
Zimbabwe & $30(2006)$ & $1,324(2004)$ & $2,086(2004)$ \\
\hline
\end{tabular}

healthcare worker resources also have high maternal mortality rates (Table 2).

At present in Uganda there are approximately 14 physician-anesthesiologists for a population of more than 30 million people; 12 of these providers work in government hospitals [6, 11]. Training positions in the postgraduate programs are unfilled yearly because of the difficulty in recruiting and funding trainees. There are only 10 anesthesia residents in training positions out of a total of 47 possible positions nationwide. The annual cost of training for one surgeon or anesthesiologist is approximately $\$ 3,500$. Half of this is tuition-fees alone, as the residents have to pay the university to allow them to enter specialist training, which is considered a postgraduate degree. This cost is nearly 10 times the estimated mean annual household income in Uganda.

The problem is similar elsewhere in sub-Saharan Africa. In neighboring Kenya (population 32 million) only 13 of a total of 120 anesthesiologists work in public hospitals. The remainder are in private practice in the capital, Nairobi, with very few serving rural areas. There are a few hundred surgeons at Kenyatta National Hospital, the National referral center and teaching hospital, yet there are only nine anesthesiologists. The problem is similar in rural Kenya, with just 1 anesthesiologist to 13 surgeons [23]. 
To put this in perspective, compared to the ratio of approximately one physician anesthesia provider per 2 million population in Uganda, in the USA the ratio is an estimated 1 anesthetic provider per 4,000 population, with the US workforce of 70,000 anesthesia providers almost equally divided between physician anesthetists and nurse anesthetists (CRNAs). Between them they perform over 40 million surgeries each year on a population of approximately 300 million people [24]. The UK has one physician-anaesthetist for every patient undergoing surgeryaround 12,000 anesthetists for a population of 64 million (approximately 1:5,000) [25]. It is clear that globally the numbers are not as favorable.

In an attempt to alleviate the workforce problem, several low and middle-income countries including Uganda and Kenya have engaged in a program of utilizing of trained "anesthetic officers" and sometimes "nurse anesthetists" (with up to 300 anesthetic officers practicing in each of these countries). Equally successful programs have been implemented worldwide, most notably in Malawi and Mozambique, Nepal, and Iran [13, 26-30]. These officers undertake a limited amount of training (usually 18 months after high school), which qualifies them to perform basic anesthesia and perioperative management. The aim is to alleviate workforce deficiencies due to a lack of physician providers. Anesthetic officers represent a much lower level of training than nurse anesthetists in Europe or CRNAs in the USA but are most likely a key part of solving the anesthesia workforce crisis. In spite of some successes, all are faced with problems related to initial training, maintenance of skills, and oversight. This is not helped by an estimated need for at least 1,000 more anesthetic personnel just to work within the existing infrastructure in each country in sub-Saharan Africa alone [23].

While successful in many areas, control of anesthetic officer training programs in some countries has been taken away from mainstream academic or physician-led anesthesia training and oversight. As a result the quality and service provided by anesthetic officers is variable. This variation in quality has proven significantly detrimental to the perception of anesthesia providers by other physicians and patients and has affected recruitment and retention of physician-anesthesiologists. The lack of physician providers in LMICs also limits professional respect, and many report that physician anesthesia providers do not command the same status as other physicians. This negative perception of the profession is also compounded by a significantly high mortality rate associated with anesthesia (as much as 1 death per 144 cases), which is very often ascribed to lack of training and oversight of the anesthesia provider combined with infrastructure and capacity issues [11, 16-19].

Even with evidence of the depth and breadth of the deficiencies in workforce and capacity, solutions are limited, as most LMICs do not have the monetary resources available to recruit, train, and maintain the physician workforce in a sustainable manner. Even where training is available, the migration of healthcare workers to resourcerich environments is a longstanding and ongoing obstacle to sustainability [2]. Anesthesiologists and other perioperative healthcare workers in low and middle-income countries are very poorly paid. In sub-Saharan African countries, engineers are paid more than doctors, and nurses command about $50 \%$ of the salary of teachers. A recent study suggested that the solution was "capital intensive and time consuming: even if the funds materialized, about 600 additional medical and nursing schools and more than two decades would be needed to close the gap" [3].

Poor working conditions and limited professional recognition are also a barrier to recruitment and retention in LMICs. This reality is amplified by deteriorating infrastructure and scarce medical supplies, leading to a lack of productivity. Such factors easily dampen morale among health workers. Studies from Tanzania indicated that, in some settings, health workers spend only 50-60\% of their time on productive activities. The rest might be spent trying to "fix the system" or to find a part for something that is broken or waiting for it to be repaired or replaced or merely being unable to work due to a lack of other workers (e.g., surgeons but no anesthesiologists or vice versa). Bureaucracy is also reported as a challenge, and it has been reported that some district medical officers in Tanzania spent more than 25 days during any 3-month period writing reports [12].

A fundamental lack of infrastructure compounds the workforce issues. A recent study looking at capacity and equipment for the safe delivery of anesthesia in Uganda indicated that only $23 \%$ of hospitals reported having a safe environment for adults, only $13 \%$ for children, and less than $6 \%$ are safe for cesarean section.

Many hospitals also rely on donated equipment rather than on a defined budget. Without sustainable biomedical support not only for existing equipment but also for equipment that is donated, this is neither a reliable nor a sustainable solution. If donations are part of an infrastructure solution, they must meet a specified unmet need in the host country. For this purpose, the WHO produced a comprehensive document on this subject advising donors about appropriate medical donations [31]. Some recent improvements in anesthesia practices in LMICs, with specific advances in patient safety and improved outcomes offer an example of the impact of anesthesia on morbidity and mortality rates. Anesthesia education and training, research, applied technology, and subsequent changes in the practice of monitoring patients has lead the way in patient safety and improved surgical outcomes over the last 50 years [11]. 
Future programs aimed at addressing the critical shortage of anesthesia providers must address the need for infrastructure by combining capacity building with programs to expand the workforce. A sound physician-anesthesiologist base is an essential requirement for appropriate oversight, training, and recruitment of future physicianspecialists, paramedical technicians, and assistants $[3,6,7$, $9,25,27,28,30,32,33]$. To be sustainable, any solution must include appropriate incremental changes to existing infrastructure rather than attempt to impose ideals perhaps originally designed for a more "infrastructure-rich" environment. The utilization and appropriate support of anesthetic officers or similarly trained nurses is a key part of this expansion process. Attracting more medical students and recent medical graduates to apply for specialist training positions also needs addressing [34]. Incentives are important but do not need to be monetary. Recent study in Uganda has shown that medical providers, trainees, and allied healthcare workers place a very high value on a collaborative effort aimed at education and improving the workplace and learning environment [6, 33, 35-37]. These simple interventions have been shown to help recruit as well as retain specialist trainees.

\section{Conclusions}

The global workforce crisis in anesthesia is an important problem in need of urgent attention. It is complicated by many factors, not least of which is the lack of current data on the numbers and types of anesthesia providers in low and middle income countries. Recognition of the crisis by the global community is clearly tied to quantifying the magnitude and origins of the problem, ultimately leading to possible solutions. This first preliminary report proposes to define the absolute deficiencies and to advocate for sustainable solutions. Future interventions must closely link local capacity building with collaborative efforts concentrating on education and attention to specific and unmet needs.

Open Access This article is distributed under the terms of the Creative Commons Attribution Noncommercial License which permits any noncommercial use, distribution, and reproduction in any medium, provided the original author(s) and source are credited.

\section{References}

1. World Bank. http://web.worldbank.org. Accessed 15 July 2009

2. Chen L, Evans T, Anand S et al (2004) Human resources for health: overcoming the crisis. Lancet 364:1984-1990

3. Conway MD, Gupta S, Khajavi K (2008) Addressing Africa's health workforce crisis. McKinsey Quart 98-105
4. Crisp N, Gawanas B, Sharp I (2008) Training the health workforce: scaling up, saving lives. Lancet 371:689-691

5. Jamison DT (2006) World Bank. Disease and mortality in SubSaharan Africa. World Bank, Washington, DC

6. Ozgediz D, Galukande M, Mabweijano J et al (2008) The neglect of the global surgical workforce: experience and evidence from Uganda. World J Surg 32:1208-1215

7. Ozgediz D, Kijjambu S, Galukande M et al (2008) Africa's neglected surgical workforce crisis. Lancet 371:627-628

8. Ozgediz D, Riviello R (2008) The "other" neglected diseases in global public health: surgical conditions in sub-Saharan Africa. PLoS Med 5:e121

9. Ozgediz D, Riviello R, Rogers SO (2008) The surgical workforce crisis in Africa: a call to action. Bull Am Coll Surg 93:10-16

10. Jamison D (2006) World Bank. Disease control priorities project. Disease control priorities in developing countries. Oxford University Press/World Bank, Washington, DC

11. Hodges SC, Mijumbi C, Okello M et al (2007) Anaesthesia services in developing countries: defining the problems. Anaesthesia 62:4-11

12. Conway MD, Gupta S, Prakash S (2006) Building better partnerships for global health. McKinsey Quart

13. Mullan F, Frehywot S (2007) Non-physician clinicians in 47 subSaharan African countries. Lancet 370:2158-2163

14. Ozgediz D, Jamison D, Cherian M et al (2008) The burden of surgical conditions and access to surgical care in low- and middle-income countries. Bull WHO 86:646-647

15. Jochberger $S$, Ismailova $F$, Lederer $W$ et al (2008) Anesthesia and its allied disciplines in the developing world: a nationwide survey of the Republic of Zambia. Anesth Analg 106:942-948 table of contents

16. Hansen D, Gausi SC, Merikebu M (2000) Anaesthesia in Malawi: complications and deaths. Trop Doct 30:146-149

17. Heywood AJ, Wilson IH, Sinclair JR (1989) Perioperative mortality in Zambia. Ann R Coll Surg Engl 71:354-358

18. Ouro-Bang'na Maman AF, Tomta K, Ahouangbevi S et al (2005) Deaths associated with anaesthesia in Togo, West Africa. Trop Doct 35:220-222

19. Walker IA, Wilson IH (2008) Anaesthesia in developing countries-a risk for patients. Lancet 371:968-969

20. World Health Organization (2009) Health systems statistics, Geneva. http://www.who.int/whosis/whostat/2009/en/print.html. Accessed 15 July 2009

21. Ozgediz D, Dunbar P, Mock C et al (2009) Bridging the gap between public health and surgery: access to surgical care in lowand middle-income countries. Bull Am Coll Surg 94:14-20

22. World Health Organization. The World Health Report 2006: Working Together for Health, Geneva, World Health Organization. http://www.who.int/whr/2006/en/. Accessed 15 July 2009

23. African Medical Research and Education Foundation (2009) Shortage of personnel hurting delivery of anaesthesia in Africa. Available at www.amref.org. Accessed 15 July 2009

24. Egger Halbeis CB, Schubert A (2008) Staffing the operating room suite: perspectives from Europe and North America on the role of different anesthesia personnel. Anesthesiol Clin 26:637-663 vi

25. Walker I, Wilson I, Bogod D (2007) Anaesthesia in developing countries. Anaesthesia 62(suppl 1):2-3

26. Coghlan CJ, Towey RM (1979) Anaesthesia by medical assistants (clinical officers) 25 years experience in Kenya. East Afr Med J 56:244-247

27. Fenton PM (1991) Anaesthesia training in Malawi. Trop Doct 21:156-158

28. Soyannwo OA, Elegbe EO (1999) Anaesthetic manpower development in West Africa. Afr J Med Sci 28:163-165

29. Spence AA (1977) Anaesthesia in Africa. Br J Anaesth 49:733734 
30. Zimmerman M, Lee M, Retnaraj S (2008) Non-doctor anaesthesia in Nepal: developing an essential cadre. Trop Doct 38:148150

31. Organization WorldHealth (2000) Guidelines for health care equipment donations. WHO, Geneva

32. Walker IA (2009) Con: pediatric anesthesia training in developing countries is best achieved by out of country scholarships. Paediatr Anaesth 19:45-49

33. Wilson IH (2009) Con: anesthesia for children in the developing world should be delivered by medical anesthetists. Paediatr Anaesth 19:39-41

34. Faponle AF (2002) Anaesthesia as a career-the influence of undergraduate education in a Nigerian Medical School. Niger Postgrad Med J 9:11-12
35. Ozgediz D, Wang J, Jayaraman S et al (2008) Surgical training and global health: initial results of a 5-year partnership with a surgical training program in a low-income country. Arch Surg 143:860-865 discussion 865

36. Walker IA, Morton NS (2009) Pediatric healthcare-the role for anesthesia and critical care services in the developing world. Paediatr Anaesth 19:1-4

37. Global Partners in Anesthesia and Surgery (2009) Available at www.globalPAS.org. Accessed 15 July 2009 